\title{
Using H.264 Codec Remote Conference System to Realize Credit Transfer of Global MOT Course at Yamaguchi University and ASEAN Universities
}

\author{
Naoki Ohshima \\ Graduate School of Innovation and Technology Management, Yamaguchi University, Ube, Yamaguchi, Japan.
}

\begin{abstract}
How to cite this paper: Naoki Ohshima. (2021). Using H.264 Codec Remote Conference System to Realize Credit Transfer of Global MOT Course at Yamaguchi University and ASEAN Universities. The Educational Review, USA, 5(9), 367-372. DOI: 10.26855/er.2021.09.006
\end{abstract}

Received: August 9, 2021

Accepted: August 31, 2021

Published: September 28, 2021

Corresponding author: Naoki Ohshima, Graduate School of Innovation and Technology Management, Yamaguchi University, Ube, Yamaguchi, Japan.

Email: nohshima@yamaguchi-u.ac.jp

\begin{abstract}
The Graduate School of Innovation and Technology Management, Yamaguchi University has been studying with ASEAN universities to establish a framework for the development of international human resource for Management of Technology in the ASEAN region. In order to complete this framework, it is necessary to consider both software for class credit transfer, code sharing, and curriculum sharing, and hardware for a stable international distance learning system. In this paper, we discuss an international distance learning system using H.264 codec video conferencing system to implement high quality mutual distance learning between Yamaguchi University and several universities in the ASEAN region (Indonesia, Malaysia, Thailand, and Vietnam). Currently, the installation of H.264 codec videoconferencing system equipment in each university is almost complete. In the classroom of Yamaguchi University, one H.264 codec, two high-resolution cameras (one is a lecturer view camera and the other is a classroom view camera) and two video devices (a large flat panel display and a high-resolution laser projector) have been installed. In this paper, we report on the trial results and future prospects of remote sessions using the H.264 equipment installed at our university.
\end{abstract}

\section{Keywords}

Emote Tele-Conference System, Course Sharing, Credit Transfer Course

\section{Introduction}

The Graduate School of Innovation and Technology Management, Yamaguchi University is a professional graduate school of management of technology for working graduate students. Since its establishment in 2005, the school has promoted problem-solving learning that incorporates active learning and other learning methods and has built up an achievement in technology management education in Japan.

With the aim of broadening the scope of technology management education cultivated up to now and fostering human resources who can play an active role on a global scale, the Asia Innovation Center was established in 2015 as an educational base for fostering highly skilled professionals who can promote open innovation across national borders, academic fields, and industry-academia boundaries in cooperation with leading universities in ASEAN countries. The professors of Yamaguchi University's Graduate School of Technology Management have taken the lead in developing the environment for implementing global MOT education. Therefore, as a cost-effective means of embodying the spread of global MOT education, the implementation of exchange classes through remote connection will be consid- 
ered.

Before our efforts, many distance lectures had been attempted. Twenty years ago, distance lectures were referred to as long distance lectures. Twenty years ago, distance lectures were known as long-distance lectures, and the specifications of the communication environment were lower than today, so establishing a two-way connection in real time itself was labour-intensive and costly (Barker, Frisbie, \& Patrick, 1989).

In 2005, a remote lecture using a video conferencing system was held between Gifu University in Japan and the University of Sydney in Australia (Toshihiro et al., 2005). At that time, the international Internet connection was enhanced, which made it possible to transmit video via IP connection. The remote lecture between Gifu University and the University of Sydney was conducted by bi-directionally transmitting camera images and audio to each other through a video monitor. The signal processing algorithm for the video transmission was MPEG codec, so the only information that could be transmitted was video and audio (Takahiro et al., 2006).

With the development of the Internet and the expansion of network capacity, distance learning systems have gradually shifted from analog television broadcasting to digital broadcasting via IP connections, and a variety of new distance learning methods have become available (Riehl, 1987; Riehl, 1990), the development of modular curricula for IP-connected distance learning is discussed (Muilenburg \& Berge, 2001), ten technical barriers to distance learning are discussed in the early stages of Internet education.

David Kember and John Dekkers (1987) focused on supporting the learning of students studying by distance learning. Gail Hart (1990) reported on the results of distance education for new college graduates and experienced nurses. Chris Dede (1996) attempted to articulate three conceptual frameworks (knowledge web, virtual community, and shared synthetic environment) for understanding new types of educational messages that enable distributed learning. Thomas $\mathrm{F}$. Stafford (2005) investigated students' motivations for using the Internet when Internet-based distance learning was first becoming popular.

Elizabeth L. Burd Shamus et al. (2015) discussed Massive Open Online Courses (MOOCs) as an example of transformation in education with the expansion of the Internet. They then attempted to redefine the position and role of universities as traditional on-site educational institutions. Teresa G. Weldy (2018) examined students' perceptions and experiences related to different ways of delivering courses, such as blended and online formats, in higher education institutions. Emily K. Faulconer and Amy B Gruss (2018) attempted to compare the learning effects in traditional face-to-face practicum and non-traditional online, distance, or distant practicum. Serpil Kocdar, Aras Bozkurt, and Tulay G. Dogan (2020) conducted text mining and social network analysis for distance learning in engineering and surveyed 120 articles.

The means of remote lecture adopted in the above cases is two-way communication through video and audio telecommunication, and multiple transmission is not adopted to share lecture materials simultaneously. We have concluded that in order to diffuse MOT education globally, it would be effective to use a remote videoconferencing system with an H.264 multiplex transmission codec that transmits the lecturer's image and lecture materials (slide materials projected on a projector) at the same time and conduct remote lectures with a sense of realism.

In this paper, we report on the process of constructing a framework for international lectures using remote systems in collaboration with universities in Malaysia, Indonesia, Thailand, and Vietnam, and on the H.264 codec remote conference system that was introduced as a tool for conducting lectures.

\section{Background}

In order for Japan to maintain its economic growth, it is essential to create sustainable innovations. It is necessary to create innovations that will be widely accepted overseas, especially in the Asian region, especially in the fast-growing ASEAN countries, rather than innovations that are completed domestically.

Innovation is not about developing new technologies. The essence of innovation is the "creative process" of succeeding as a business while taking into account the social, economic, and cultural contexts.

Human resources who can drive such innovation are required to be able to see things from a multifaceted perspective of technology and management, and to understand the diversity of culture and society while collaborating with people in the Asian economic zone to create mutually beneficial business models.

Yamaguchi University has established the Asia Innovation Center as an "Asia-wide practical innovation education center" with the aim of implementing educational programs to foster global engineers that transcend national borders in order to develop such human resources (Global MOT Education Project). 


\section{Collaboration with Overseas Universities}

\subsection{Global MOT Education Consortium}

We formed a consortium for global MOT education in cooperation with the following universities: Bandung Institute of Technology Business School, Indonesia; Malaysia-Japan International Institute of Technology, Universiti Teknologi Malaysia; Mara Institute of Technology Business School; Chiang Mai University Business School, Thailand; and Da Nang University of Science and Technology Business School, Vietnam. A consortium for global MOT education was formed in cooperation with the following universities.

\subsection{Study of Remote Tele-Conference System}

In this global MOT education project, the H.264 codec-based teleconference system was introduced as a means of communication and communication between Yamaguchi University and each university.

Yamaguchi University has been using the H.264 codec-based remote conference system for remote lectures within the university and remote training at multiple campuses. The feature of the H.264 codec-based remote conference system is that it can deliver a clear image and sound of the lecturer and video of the PC. As long as the Internet communication environment is available, the system can be connected to any location, both domestic and international. In addition, the H.264 codec-based teleconferencing system can easily establish a connection by simply turning on the receiver and calling the other station, since dedicated hardware is installed. In this project, we emphasized the importance of easy and stable intercommunication for faculty and students who do not have expertise in communications.

\subsection{H.264 codec-based remote conference system}

In order to establish a smooth telecommunication connection with overseas universities, it is not enough to introduce an H.264 codec-based teleconference system. Therefore, in this paper, we report a case study of the Business School of Da Nang University of Science and Technology, Vietnam, which introduced the same model of H.264 codec-based teleconference system (made by SONY) used by Yamaguchi University.

Since the H.264 codec-based teleconferencing system is basically a system for teleconferencing, it assumes a mode where both parties face each other in an equal position. We will call this mode the meeting mode.

On the other hand, in a remote class, since the system is divided into two parts, the one delivering the lecture (lecture station) and the other receiving the lecture (student station), we call this style the schooling mode.

Figure 1 shows the connection diagram of the devices for the meeting mode. The equipment to be connected consists of two remote video cameras, two flat panels (about 60 inches), one codec and one computer.

The dedicated video cameras are of a type where the video signal (HDMI cable) and control (VISCA cable) are connected separately, and the camel angle and zoom (wide: tele) can be adjusted with a remote control. Also, if the distributing and receiving stations have the same manufacturer's H.264 codec-based teleconferencing system, it is possible to adjust the other side's camera (for example, switching the camera from the Japanese side to the Vietnamese side) and perform other remote operations. By having the lecturer smoothly perform such operations, it will be possible to deliver lectures with a sense of realism to remote locations.

Next, the connection of devices for schooling mode is shown in Figure 2. In the schooling mode, the students on the remote (receiving) side are arranged so that they appear as if they are in the same classroom with the local students, as seen by the instructor on the delivering side. Also, to the students on the receiving side, the instructor on the remote (delivery) side should be arranged as if they were in the classroom with them.

In order to achieve this arrangement, the number of video monitors is increased in the schooling mode compared to the meeting mode, and they are connected to two flat panel monitors and one LCD projector. In doing so, the two flat panel monitors project the same image through a distributor (Figure 2).

In addition, at each station (distributor and receiver), each of the two cameras should be arranged so that they can capture the instructor view and the student view. Here, we have to pay attention to the priority of the cameras in the system. Due to system constraints, the primary camera will be the one that captures the student view, and the secondary camera will be the one that captures the instructor view. Figure 3 shows a picture of the arrangement of the equipment at Yamaguchi University.

\subsection{Telecommunication Connection with Overseas Universities}

In May 2018, Yamaguchi University and Da Nang University of Science and Technology were connected to demonstrate remote lectures using an H.264 codec-based teleconference system. In this demonstration, the lecture started with 
the Japanese side (Yamaguchi University) as the distribution station and the Vietnamese side (Da Nang University of Science and Technology) as the receiving side. During the course of the lecture, the Vietnamese students asked questions and the Japanese and Vietnamese students discussed each other by switching the camera to the student view.
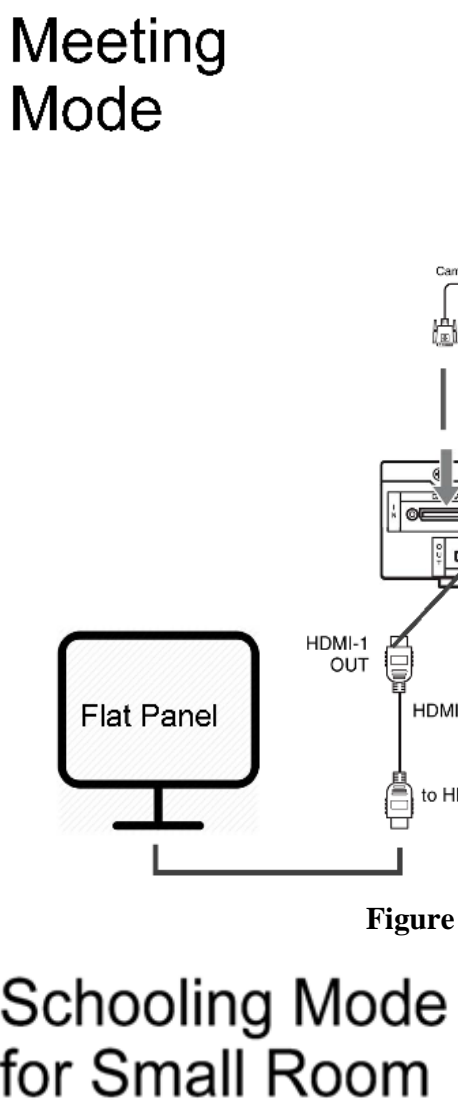

\section{Schooling Mode for Small Room}
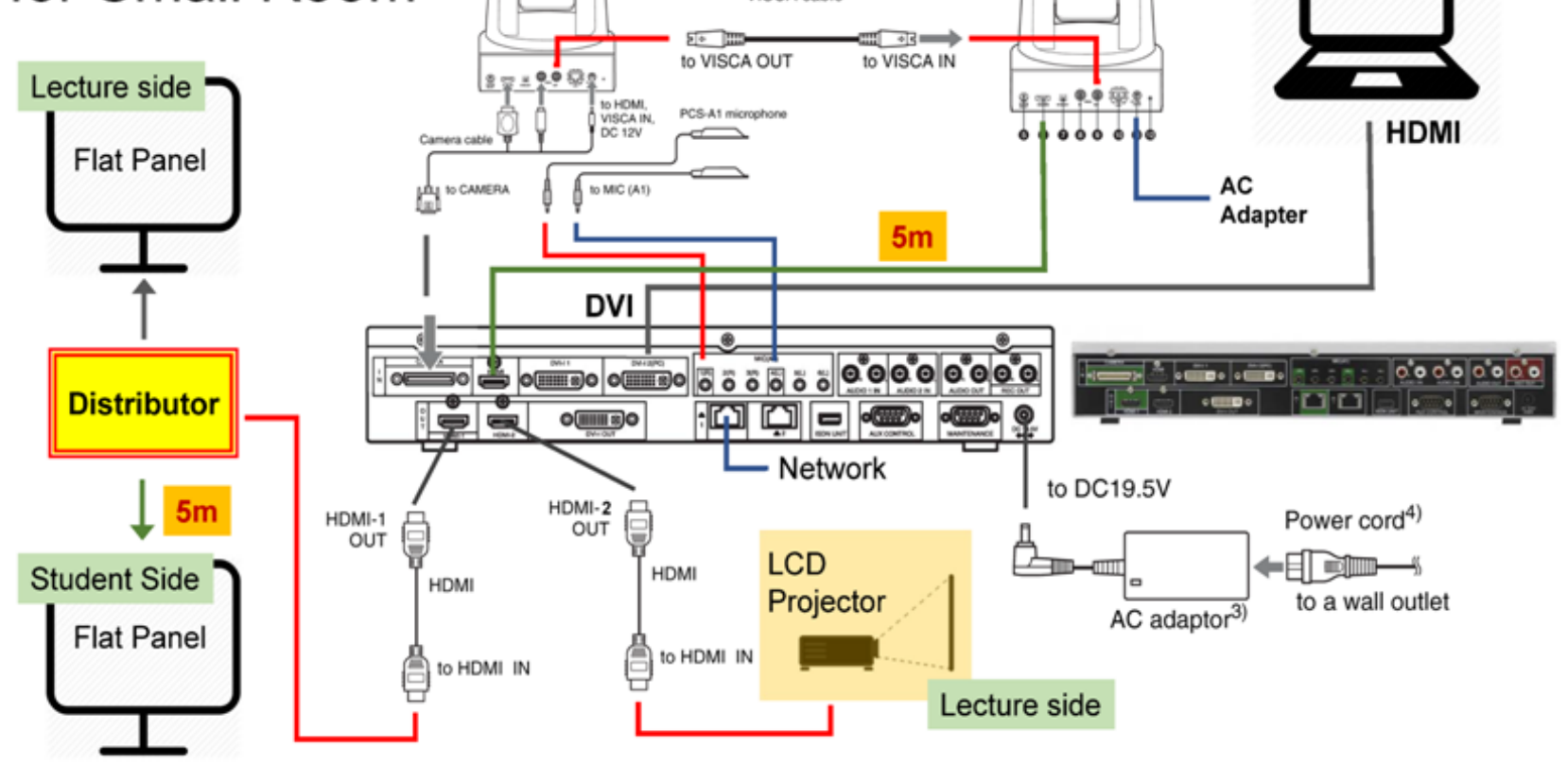

Figure 2. Connection of equipment compatible with schooling mode. 


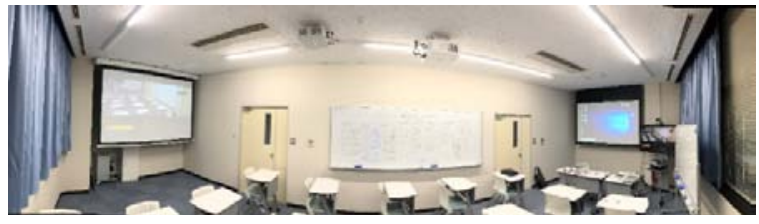

(a) Full view of lecture room introducing H.264 codec-based remote conference system.

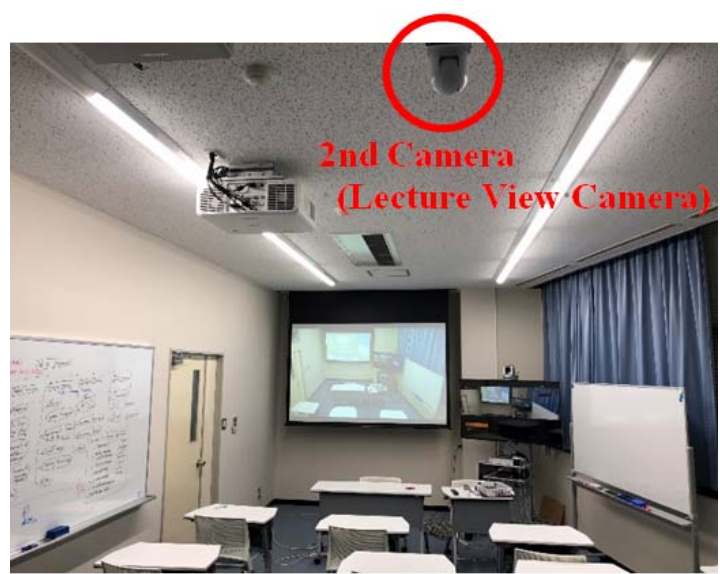

(b) The secondary camera takes a lecturer and a front screen.

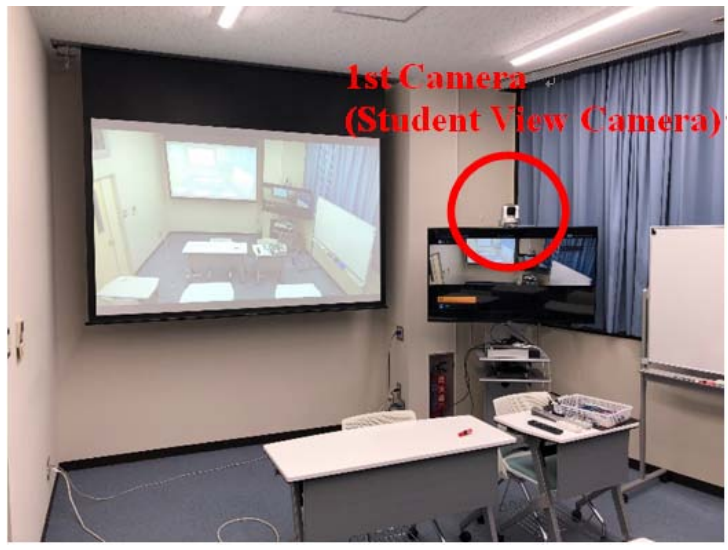

(c) Primary camera shoots the classroom from the instructor's point of view.

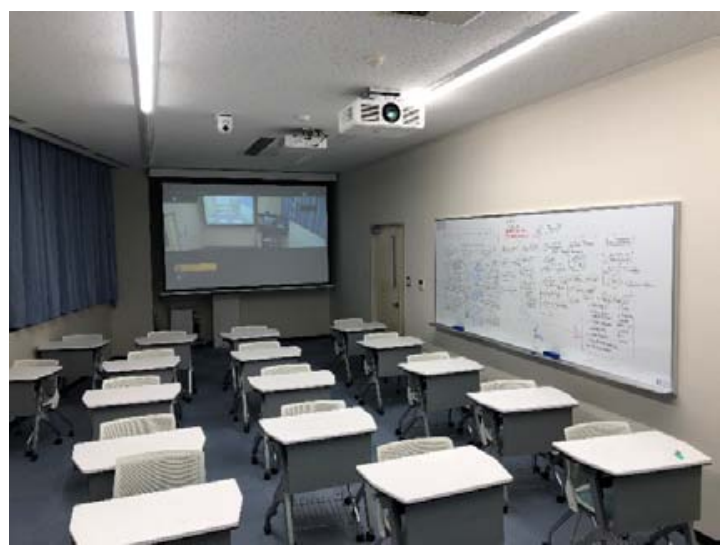

(d) Classroom viewed from the primary camera (student view).

Figure 3. In the lecture room, introducing the H.264 codec-based remote conference system, shows the arrangement and view of the primary camera and the secondary camera. 


\section{Conclusion}

Yamaguchi University has been collaborating with universities in Asian countries to implement the Global MOT Education Project and has been trying to introduce the H.264 codec-based teleconferencing system. The demonstration lecture using the H.264 codec-based teleconference system has been successfully completed. This result shows the potential of the H.264 codec-based teleconference system. In the future, we will start designing a curriculum map for the implementation of code-sharing lectures using this teleconferencing system, and also for the implementation of international exchange classes based on the premise of credit transfer.

\section{References}

Aoyagi Takahiro, Imai Ako, Ema Satoshi, Kato Naoki, Kobayashi Kazutaka, Nishizawa Yasuo, Hirota Norio, Matsubara Masaya, Yamada Toshihiro, and Sonia Mycak. (2006). Approaches to International Distance Learning Using the Module Exchange Method. Journal of Multimedia Aided Education Research, Volume 3, No. 1, pp. 9-18.

Bruce O. Barker, Anthony G. Frisbie, and Kenneth R. Patrick. (1989). Concepts: Broadening the definition of distance education in light of the new telecommunications technologies, American Journal of Distance Education, Volume 3, pp. 20-29.

Chris Dede. (1996). The evolution of distance education: Emerging technologies and distributed learning, American Journal of Distance Education, Volume 10, pp. 4-36.

David Kember and John Dekkers. (1987). The role of study centres for academic support in distance education. Journal of Distance Education, Volume 8, pp. 4-17.

Elizabeth L. Burd and Shamus P. Smith. (2015). Exploring Business Models for MOOCs in Higher Education. Innovative Higher Education, Volume 40, pp. 37-49.

Emily K. Faulconer and Amy B. Gruss. (2018). A Review to Weigh the Pros and Cons of Online, Remote, and Distance Science Laboratory Experiences. International Review of Research in Open and Distributed Learning, Volume 19, Issue 2, DOI: https://doi.org/10.19173/irrodl.v19i2.3386.

Gail Hart. (1990). Peer learning and support via audio-teleconferencing in continuing education for nurses. Journal of Distance Education, Volume 11, pp. 308-319.

Julian W. Riehl. (1987). A Curriculum Model of Telecommunications Education Requirements for the Information Systems Specialist. Journal of Computer Information Systems, Volume 27, pp. 2-4.

Julian W. Riehl. (1990). A Curriculum Model of Telecommunications Education Requirements for the Information Systems Specialist (Part II). Journal of Computer Information Systems, Volume 30, pp. 11-13.

Lin Muilenburg and Zane L. Berge. (2001). Barriers to distance education: A factor-analytic study. American Journal of Distance Education, Volume 15, Issue 2, pp. 7-22.

Serpil Kocdar, Aras Bozkurt, and Tulay G. Dogan. (2020). Engineering through distance education in the time of the fourth industrial revolution: Reflections from three decades of peer reviewed studies. Computer Applications in Engineering Education, Volume 29, Issue 4, DOI: https://doi.org/10.1002/cae.22367.

Teresa G. Weldy. (2018). Traditional, Blended, or Online: Business Student Preferences and Experience with Different Course Formats. e-Journal of Business Education and Scholarship of Teaching, Volume 12, pp. 55-62.

Thomas F. Stafford. (2005). Understanding motivations for Internet use in distance education. IEEE Education Society, IEEE Transactions on Education, Volume 48, pp. 301-306.

Yamada Toshihiro, Imai Ako, Ema Satoshi, Kato Naoki, Kobayashi Kazutaka, Nishizawa Yasuo, Matsubara Masaya, Yamato Ryusuke, Hugh Clarke, and Iwashita Mami. (2005). Japanese Classes delivered to the University of Sydney using Videoconferencing, Annual report of the Faculty of Education, Gifu University. Humanities and Social Sciences, Volume 7, pp. 19-41. 